\title{
Treatment failure in pneumonia: impact of antibiotic treatment and cost analysis
}

\author{
S.R. Ott*, B.M. Hauptmeier", C. Ernen ${ }^{\ddagger}$, P.M. Lepper ${ }^{+}$, E. Nüesch ${ }^{\S, f}$, M.W. Pletz**, \\ J. Hecht ${ }^{\# \#}$, T. Welte ${ }^{\text {बף }}$ and T.T. Bauer $\# \#$
}

ABSTRACT: The aim of this study was to investigate treatment failure (TF) in hospitalised community-acquired pneumonia (CAP) patients with regard to initial antibiotic treatment and economic impact.

CAP patients were included in two open, prospective multicentre studies assessing the direct costs for in-patient treatment. Patients received treatment either with moxifloxacin (MFX) or a nonstandardised antibiotic therapy. Any change in antibiotic therapy after $>72 \mathrm{~h}$ of treatment to a broadened antibiotic spectrum was considered as TF.

Overall, 1,236 patients (mean \pm SD age $69.6 \pm 16.8 \mathrm{yrs}, 691$ (55.9\%) male) were included. TF occurred in $197(15.9 \%)$ subjects and led to longer hospital stay (15.4 \pm 7.3 days versus $9.8 \pm 4.2$ days; $p<0.001)$ and increased median treatment costs $(€ 2,206$ versus $€ 1,284 ; p<0.001) .596$ (48.2\%) patients received MFX and witnessed less TF (10.9\% versus $20.6 \% ; p<0.001)$. After controlling for confounders in multivariate analysis, adjusted risk of TF was clearly reduced in MFX as compared with $\beta$-lactam monotherapy (adjusted OR for MFX $0.43,95 \% \mathrm{Cl} 0.27-0.68$ ) and was more comparable with a $\beta$-lactam plus macrolide combination (BLM) (OR 0.68, 95\% $\mathrm{CI} 0.38-1.21$ ).

In hospitalised CAP, TF is frequent and leads to prolonged hospital stay and increased treatment costs. Initial treatment with MFX or BLM is a possible strategy to prevent TF, and may thus reduce treatment costs.

KEYWORDS: Community-acquired pneumonia, cost effectiveness, moxifloxacin, treatment failure

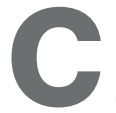
ommunity-acquired pneumonia (CAP) is a frequent disease with important implications for healthcare systems worldwide. Based on a recent report from Germany using the database of the German programme for quality in healthcare, the annual incidence of hospitalised CAP is estimated at $2.75-2.96$ per 1,000 inhabitants, resulting in 200,000-240,000 annual CAPassociated hospitalisations [1] Therefore, the treatment of CAP is associated with a significant use of healthcare resources. The total direct and indirect costs of pneumonia in Europe were estimated to be $€ 10$ billion, of which more than one-half were direct costs [2]. Although only $\sim 20 \%$ of all CAP patients require in-patient treatment, costs due to in-patient treatment account for almost $90 \%$ of the direct costs and, thus, represent a considerable financial burden. Since 2004, reimbursement of hospitals in the statutory health insurance system in Germany is based on diagnosis-related groups. Therefore, from the perspective of the hospital, any means of reducing economic costs per case is meaningful.

Most CAP patients are treated empirically, with the inability to predict the risk of treatment failure (TF). TF occurs in $\sim 15 \%$ of all patients with CAP [3-6], and usually leads to a prolonged hospital stay [7]. In a prospective study, we demonstrated recently that length of stay and the need for intensive care treatment were the major determinants of costs [8]. As the length of stay (LOS) is an important variable affecting treatment costs, the primary issue of the present study was to investigate whether TF has a negative impact on the LOS and, therefore, direct treatment costs in patients hospitalised for CAP.

Initial treatment with a fluoroquinolone has shown to be associated with a faster resolution of signs and symptoms of CAP and probably reduces the risk of $\mathrm{TF}$ in comparison with nonstandardised therapies [3, 9-11]. Therefore, we also evaluated the influence of initial fluoroquinolone (moxifloxacin; MFX) therapy on the frequency of TF and overall cost-effectiveness in CAP treatment.

\section{METHODS}

Between January 2002 and December 2005, patients hospitalised for CAP in 22 community hospitals in Germany were included in two consecutive cohort studies with identical study

\section{AFFILIATIONS}

*Dept of Respiratory Medicine, University Hospital Berne (Inselspital) and University of Berne ${ }^{\S}$ Institute of Social and Preventive Medicine (ISPM), University of Berne,

${ }^{f}$ CTU Berne, Berne University Hospital, Berne, Switzerland, \#Dept of Pneumology, University Hospital Bergmannsheil, Bochum, Germany,

"Institute of Empirical Health Economics, Burscheid, ${ }^{+}$Dept of Internal Medicine V Pneumology, Allergology and Respiratory Critical Care Medicine, University Hospital of Saarland, Homburg,

**Division of Gastroenterology, Hepatology and Infectious Diseases, Jena University Hospital, Jena, Germany,

\#\# Dept of Pneumology, University of Hannover, School of Medicine,

Hannover, Germany, and

"Dept of Pneumology, HELIOS Klinikum Emil von Behring, Chest Hospital Heckeshorn, Berlin, Germany.

CORRESPONDENCE

S.R. Ott

Inselspital

University Hospital and University

of Berne

Dept of Pneumology

3010 Berne

Switzerland

E-mail: sebastian.ott@insel.ch

Received:

June 082011

Accepted after revision:

Aug 142011

First published online:

Sept 292011

European Respiratory Journal Print ISSN 0903-1936 Online ISSN 1399-3003 
design. The study design was open, actively controlled and prospective. Pneumonia was defined according to usual the criteria (proof of a new pulmonary infiltrate on chest radiography, and at least two of the following symptoms and signs of CAP: 1) cough; 2) pleuritic chest pain; 3) shortness of breath; 4) temperature $>38^{\circ} \mathrm{C}$; and 5) crackles on auscultation). Patients were included if they received at least one dose of intravenous antibacterial treatment and in the absence of any of the following exclusion criteria: 1) age $<18$ yrs, or pregnancy or lactating/ breast feeding; 2) hospital admission within the previous 2 weeks; 3) participation in any clinical trial during the period of observation; 4) pneumonia as an expected terminal event of a severe chronic disabling comorbidity; and 5) discharge from hospital at the patient's request.

Both studies were approved by ethical committees, and informed consent was judged not to be necessary due to the observational nature of the study and the fact that no intervention was taken on the process of CAP treatment. All patients from both study periods were observed as one cohort and were divided into two groups: the first group comprised all patients who had received initial treatment with i.v. MFX (group M); the second group consisted of patients who had received any other initial antibiotic (group S). This study needed to be actively controlled to reduce two biases due to possible selective recruitment and differences in therapy between hospitals. First, since we wanted to test the hypothesis that treatment failure occurs more often in one treatment group, it was necessary to restrict the recruitment to one group per institution. As the study was open label and not randomised, an advantage seen or even only felt by the investigators in one institution would have possibly led to biased recruitment.

Secondly, we could not assume that treatment outcomes were homogenously distributed among facilities. As numbers of subjects, and thus the recruiting potential, and/or speed of recruitment also may have varied between hospitals, we minimised the potential of overrepresentation of results from single institutions by restricting recruitment to the first 30 consecutive patients for all hospitals.

TF was defined as the need to switch to another antibiotic regimen $\geqslant 72 \mathrm{~h}$ after initial treatment resulting in an expansion of the antibiotic spectrum by adding another agent or replacing the initial antibiotic by another of the same class with a broader antibacterial spectrum. Modifications of antibiotic treatment resulting in a narrowed antimicrobial coverage were considered as "de-escalation" and not as TF.

\section{Data collection and evaluation}

All patients were assessed on hospital admission and followed during hospital stay until discharge, according to a standardised data sheet. The following parameters were evaluated: date of presentation (month, year); age; sex; weight; smoking habits (current smokers or ex-smokers $\geqslant 1 \mathrm{yr}$ ); comorbidities; mode of hospital admission; residence in nursing home; duration of symptoms; clinical symptoms (body temperature, respiratory rate, heart rate, arterial systolic and diastolic blood pressure, pneumonia-associated confusion, stupor, or coma); blood gas analysis; chest radiography (number of lobes affected and prescence of pleural effusion); laboratory parameters (haematocrit, blood urea nitrogen, sodium and blood glucose); and intensive care unit admission and/or mechanical ventilation. The following three end-points were defined: hospital discharge, conclusion of the in-patient treatment due to CAP and death. For comparison of pneumonia severity within groups, the Pneumonia Severity Index (PSI) and CURB-65 score (confusion of new onset, urea $>7 \mathrm{mmol} \cdot \mathrm{L}^{-1}$, respiratory rate of $\geqslant 30$ breaths $\cdot \mathrm{min}^{-1}$, blood pressure $<90 \mathrm{mmHg}$ systolic or diastolic blood pressure $\leqslant 60 \mathrm{mmHg}$, and age $\geqslant 65 \mathrm{yrs}$ ) were calculated for each patient on admission $[12,13]$.

\section{Microbiology}

As the main issue was to calculate the real-life direct treatment costs, no standardised microbiological work-up was recommended or performed. Therefore the requests for microbiological evaluation were left to the discretion of the treating physician, in order not to influence overall costs.

\section{Cost calculation}

All cost calculations were performed by economists on the basis of the case report forms and a standardised hospital controller interview. Direct costs were defined according to DRUMMOND et al. [14] as category I (organising and operating costs within the health sector). Total costs consisted of the number of measures taken and the charge per measure. For each patient, the number of diagnostic and therapeutic measures and the duration of medical care by physicians, nurses, medical technical staff and physiotherapists were documented. For the various diagnostic and therapeutic measures, the empirical average duration of a standard treatment and therapeutic measure was documented and used to calculate costs. This was performed separately for diagnostic and therapeutic measures in the intensive and the regular care units. These average durations in hours per day were multiplied by the staff costs per hour of the respective responsible staff. The diagnostic and therapeutic costs of care per patient were then determined by multiplication of the average daily cost of care per patient (average duration in hours per day multiplied by staff costs per hour) by the number of days spent in the respective units.

Specific hotel costs per patient were calculated by the Institute of Empirical Health Economics, Burscheid, Germany. Analyses of hospital costs were blinded and, therefore, no interhospital differences can be disclosed here.

The quantity and type of administered drugs and the use of medical devices was also analysed. Total costs were then calculated from the sum of the various cost factors (see table 1). Calculated values have been rounded.

\section{Statistics}

The primary objective of the study was the evaluation of the overall economic costs associated with the in-patient treatment of CAP patients. The secondary objective was the post hoc evaluation of the impact of TF on overall treatment cost. Primary and secondary outcome variables were compared between treatment groups. Results are expressed as frequencies or as mean \pm SD unless indicated otherwise. The Chi-squared test was used to compare proportions and the unpaired t-test was used to compare means. All continuous variables were tested for normal distribution using the Kolmogorov-Smirnov test. For variables in which this test indicated non-normal distribution, the Mann-Whitney U-test was employed for comparison, and 


\section{TABLE 1 Cost calculation: composition of cost factors}

\begin{tabular}{|c|c|}
\hline Cost factor & Including \\
\hline Diagnostic measures & $\begin{array}{l}\text { Physical examination (auscultation, } \\
\text { percussion) and history } \\
\text { Chest radiography } \\
\text { Laboratory chemistry } \\
\text { Microbiology (left to the } \\
\text { physician's discretion), including } \\
\text { resistance, serology and } \\
\text { antigen testing } \\
\text { Bronchoscopy, including costs for } \\
\text { biopsy and lavage } \\
\text { Pulmonary function testing } \\
\text { Blood gas analysis } \\
\text { ECG }\end{array}$ \\
\hline $\begin{array}{l}\text { Therapeutic measures } \\
\text { (excluding drug therapy) }\end{array}$ & $\begin{array}{c}\text { Inhalation therapy } \\
\text { Supplemental oxygen } \\
\text { Physiotherapy, including mobilisation }\end{array}$ \\
\hline Drug acquisition & $\begin{array}{l}\text { All drugs indicated by the treating } \\
\text { physician to be necessary } \\
\text { for treatment of CAP }\end{array}$ \\
\hline Hotel & $\begin{array}{l}\text { Estimated costs per day and patient } \\
\text { for: administration, housekeeping } \\
\text { (e.g. gas, electricity) and food } \\
\text { for regular wards and ICUs }\end{array}$ \\
\hline Staff & $\begin{array}{c}\text { Physicians } \\
\text { Technical staff } \\
\text { Physiotherapists } \\
\text { Nurses for regular wards and ICUs }\end{array}$ \\
\hline
\end{tabular}

CAP: community-acquired pneumonia; ICU: intensive care unit.

median, minimum and maximum values were reported. We analysed associations between treatment failure and type of antibiotic treatment using maximum likelihood logistic regression models. Analyses were performed crude and were adjusted for sex, age, body mass index, smoking status, chronic obstructive pulmonary disease, lung cancer, heart disease, diabetes, antibiotic pre-treatment, CURB-65 and PSI. p-values for associations were derived from Wald tests. The significance level of all analyses was set to $5 \%$ and p-values are reported. All data were analysed and processed using statistical software (Statistical Package for Social Sciences, version 15.0 (SPSS, Chicago, IL, USA), or Stata release 11 (Stata Corp, College Station, TX, USA)) on the Windows XP operating system (Microsoft, Redmond, WA, USA).

\section{RESULTS}

\section{Study population and TF}

A total of 1,236 patients were enrolled (580 patients in the first study period and 756 in the second study period). Table 2 summarises the demographic characteristics, smoking status, comorbidity, antibiotic pre-treatment and initial severity of disease, as calculated by CURB-65 and PSI.

TF occurred in 197 of 1,236 patients (15.9\%). Most TF occurred early in the course of treatment; 77 cases occurred by day 3 , corresponding to a prevalence of early failures of $6.2 \%$ in the total cohort (fig. 1). There was no difference in the timing of TF

\begin{tabular}{|c|c|c|c|}
\hline & Total & Success & TF \\
\hline Subjects n & 1236 & 1039 & 197 \\
\hline Male sex & 691/1235 (55.9) & $582 / 1038(56.0)$ & 109/197 (55.3) \\
\hline Age yrs & $69.6 \pm 16.8$ & $69.4 \pm 16.9$ & $70.8 \pm 16.2$ \\
\hline $\mathrm{BMI}^{\#} \mathbf{k g} \cdot \mathbf{m}^{-2}$ & $25.7 \pm 4.9$ & $25.7 \pm 4.9$ & $25.8 \pm 5.1$ \\
\hline Current smoker & 264/1194 (22.1) & 225/1003 (22.4) & 39/191 (20.4) \\
\hline COPD & $341 / 1235$ (27.6) & 295/1038 (28.4) & 46/197 (23.4) \\
\hline LC & 31/1235 (2.5) & 24/1038 (2.4) & 7/197 (3.6) \\
\hline CHF & 378/1235 (30.6) & 302/1038 (31.7) & $76 / 197(38.6)^{\bullet}$ \\
\hline DM & 443/1235 (35.9) & $361 / 1038$ (44.5) & 82/197 (41.6) \\
\hline $\begin{array}{l}\text { Antibiotic } \\
\text { pre-treatment }\end{array}$ & $144 / 1160(12.4)$ & 126/983 (12.3) & $18 / 177(9.2)^{\circ}$ \\
\hline \multicolumn{4}{|l|}{ CURB-65 score } \\
\hline 0 & 308 (24.9) & $274(26.4)$ & 34 (17.3) \\
\hline 1 & 549 (44.4) & 463 (44.6) & $86(43.7)$ \\
\hline 2 & 291 (23.5) & $228(21.9)$ & 63 (31.9) \\
\hline 3 & 78 (6.3) & $64(6.1)$ & $14(7.1)$ \\
\hline 4 & $10(0.8)$ & $10(1.0)$ & $0(0)$ \\
\hline \multicolumn{4}{|l|}{ PSI score } \\
\hline 1 & $94(7.6)$ & $80(7.7)$ & $14(7.1)$ \\
\hline 2 & $162(13.1)$ & 148 (14.2) & $14(7.1)$ \\
\hline 3 & $244(19.7)$ & 216 (20.8) & 28 (14.2) \\
\hline 4 & $536(43.4)$ & 438 (42.2) & $98(49.7)$ \\
\hline 5 & 200 (16.2) & $157(15.1)$ & $43(21.8)$ \\
\hline
\end{tabular}

Data are presented as $\mathrm{n} / \mathrm{N}(\%)$, mean $\pm \mathrm{SD}$ or $\mathrm{n}(\%)$, unless otherwise stated. TF: treatment failure; BMl: body mass index; COPD: chronic obstructive pulmonary disease; LC: lung carcinoma; CHF: congestive heart failure; DM: diabetes mellitus; CURB-65: confusion of new onset, urea $>7 \mathrm{mmol} \cdot \mathrm{L}^{-1}$, respiratory rate of $\geqslant 30$ breaths $\cdot \mathrm{min}^{-1}$, blood pressure $<90 \mathrm{mmHg}$ systolic or diastolic blood pressure $\leqslant 60 \mathrm{mmHg}$, and age $\geqslant 65 \mathrm{yrs}$; PSI: pneumonia severity index. ${ }^{\#}: \mathrm{n}=1055$. $\mathrm{p}$-value for all parameters $>0.05$, except ${ }^{\natural}: \mathrm{p}<0.01$

(early failure versus nonresponding pneumonia) between treatment groups. Comparing baseline data of successfully treated patients with failures, the rates of congestive heart failure $(\mathrm{CHF})$ and antibiotic pre-treatment were significantly different. Patients who experienced TF suffered more frequently from CHF. TF was more frequently observed in group $\mathrm{S}$ compared with group $\mathrm{M}$ (132 $(20.6 \%)$ out of 640 versus $65(10.9 \%)$ out of 596; $\mathrm{p}<0.001)$.

The rate of TF also correlated with pneumonia severity in terms of groups. In patients with mild pneumonia (CURB-65 score 0), treatment failure occurred in $34(11.0 \%)$ out of 308 patients and was, thus, below the average mean of 197 (15.9\%) out of 1,236 patients. With increasing CAP severity, a rise in TF frequency was observed from $86(15.7 \%)$ out of 549 in CURB-65 group 1 patients to $77(20.3 \%)$ out of 379 patients in subjects with more severe CAP $(\mathrm{sCAP})$ as defined by CURB-65 score $\geqslant 2(\mathrm{p}=0.004)$.

\section{Antibiotic treatment}

$596(48.2 \%)$ out of 1,236 patients were treated initially with MFX. The remaining patients received a nonstandardised antibiotic therapy (group S); in $>90 \%$, a $\beta$-lactam antibiotic was given and almost half of these patients received combination therapy, including a $\beta$-lactam plus a macrolide antibiotic (BLM). Details on antibiotic treatment are summarised in table 3. 


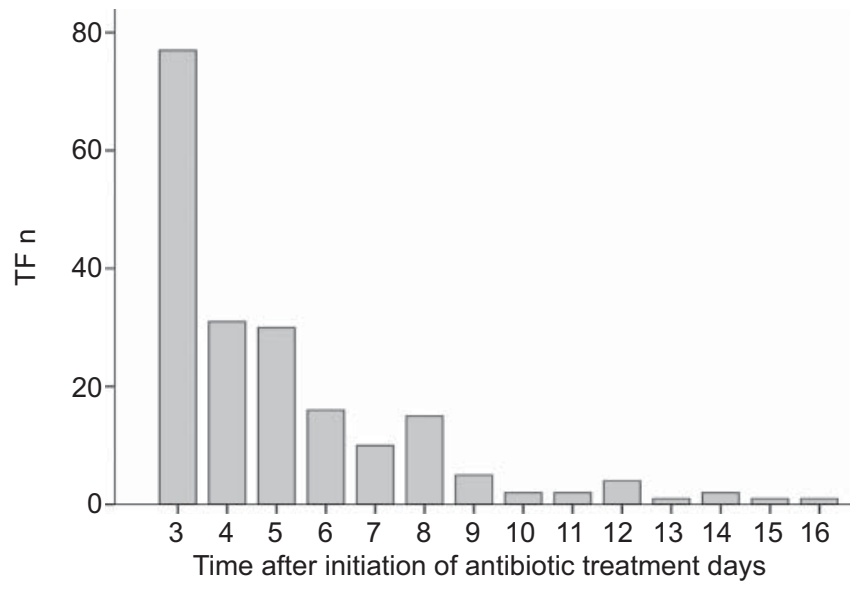

FIGURE 1. Timing of treatment failure (TF). $n=197$

Antibiotic therapy was started i.v. in all patients and was switched to oral application during the hospital stay in 809 $(65.5 \%)$ out of 1,236 patients. In patients receiving MFX, sequence therapy was more frequent in comparison with group S (471 (79.0\%) out of 536 patients versus 338 (52.8\%) out of 640 patients; $\mathrm{p}<0.001$ ), and mean duration of parenteral treatment was significantly shorter $(2.7 \pm 1.8$ versus $5.4 \pm 2.5$ days; $\mathrm{p}<0.001)$.

The subjects of both groups were very comparable with regard to baseline characteristics, except for the rate of diabetics. The number of diabetic patients was significantly higher in group M. Details on baseline demographics of the two groups are summarised in table 4.

\section{Antibiotic treatment and TF}

Depending on CAP severity, the choice of initial antibiotic treatment had an influence on the risk of TF. In group S, initial

\begin{tabular}{|c|c|c|}
\hline Variables & Group M & Group S \\
\hline Subjects $n$ & 596 & 640 \\
\hline Monotherapy & $577 / 596(96.8)$ & $351 / 640(54.8)$ \\
\hline Fluoroquininolone & $577(100)$ & $29 / 351(8.3)^{\#}$ \\
\hline$\beta$-lactam $\pm \beta$-lactamase inhibitor & & $302 / 351(82.0)$ \\
\hline Macrolide & & 13/351 (3.7) \\
\hline Others & & $7 / 351$ (2.0) \\
\hline Combination therapy & 19/596 (3.2) & $289 / 640(45.2)$ \\
\hline$\beta$-lactam $\pm \beta$-lactamase inhibitor & & 284/289 (98.3) \\
\hline +macrolide & $1 / 19(5.3)$ & $239 / 284(84.5)$ \\
\hline +fluoroquinolone & & $14 / 284(4.9)^{\#}$ \\
\hline +aminoglycoside & & $13 / 284(4.6)$ \\
\hline +lincosamide & & 9/284 (3.2) \\
\hline +nitroimidazole & & $5 / 284(1.8)$ \\
\hline$+\beta$-lactam & $17 / 19(89.5)$ & $2 / 284(0.4)$ \\
\hline +carbapeneme & $1 / 19(5.3)$ & \\
\hline +others & & 2/284 (0.4) \\
\hline
\end{tabular}

Data are presented as $\mathrm{n} / \mathrm{N}(\%)$ or $\mathrm{n}(\%)$, unless otherwise stated. ${ }^{*}$ : except moxifloxacin.

\begin{tabular}{|c|c|c|c|}
\hline \multirow[t]{2}{*}{ TABLE 4} & \multicolumn{3}{|c|}{$\begin{array}{l}\text { Demographics and pneumonia severity } \\
\text { (treatment groups) }\end{array}$} \\
\hline & Total & Group M & Group S \\
\hline Subjects $n$ & 1236 & 596 & 640 \\
\hline Male sex & 691 (55.9) & $322(54.0)$ & $369(57.6)$ \\
\hline Age yrs & $69.6 \pm 16.8$ & $69.3 \pm 15.8$ & $69.9 \pm 17.7$ \\
\hline$B M I \mathrm{~kg} \cdot \mathrm{m}^{-2}$ & $25.7 \pm 4.9$ & $26.2 \pm 4.8$ & $25.3 \pm 5.0$ \\
\hline Current smoker & $264 / 1194$ (22.1) & $124 / 587(21.1)$ & $140 / 607(23.1)$ \\
\hline COPD & $341(27.6)$ & $169(28.4)$ & 172 (26.9) \\
\hline LC & $31(2.5)$ & $20(3.4)$ & $11(1.7)$ \\
\hline CHF & $378(30.6)$ & $189(31.7)$ & $189(29.6)$ \\
\hline DM & $443 / 1235$ (35.9) & $265 / 596(44.5)$ & $178 / 639(27.9)^{\#}$ \\
\hline $\begin{array}{l}\text { Antibiotic pre- } \\
\text { treatment }\end{array}$ & $144 / 1160(12.4)$ & $62 / 580(10.7)$ & $82 / 640(14.1)$ \\
\hline \multicolumn{4}{|l|}{ CURB-65 score } \\
\hline 0 & 308 (24.9) & 157 (26.3) & 151 (23.6) \\
\hline 1 & 549 (44.4) & $268(45.0)$ & 281 (43.9) \\
\hline 2 & 291 (235) & $129(21.6)$ & $162(253)$ \\
\hline 3 & 78 (6.3) & $38(6.4)$ & $40(6.3)$ \\
\hline 4 & $10(0.8)$ & $4(0.7)$ & $6(09)$ \\
\hline \multicolumn{4}{|l|}{ PSI score } \\
\hline 1 & $94(7.6)$ & $37(6.2)$ & $57(8.9)$ \\
\hline 2 & $162(13.1)$ & $94(15.8)$ & 68 (10.6) \\
\hline 3 & $244(19.7)$ & $124(20.8)$ & $120(18.8)$ \\
\hline 4 & 536 (43.4) & $234(39.3)$ & $302(47.2)$ \\
\hline 5 & $200(16.2)$ & $107(17.9)$ & $93(14.5)$ \\
\hline
\end{tabular}

Data are presented as $n(\%)$, mean \pm SD or $n / N(\%)$, unless otherwise stated. BMI: body mass index; COPD: chronic obstructive pulmonary disease; LC: lung carcinoma; CHF: congestive heart failure; DM: diabetes mellitus; CURB-65: confusion of new onset, urea $>7 \mathrm{mmol} \cdot \mathrm{L}^{-1}$, respiratory rate of $\geqslant 30$ breath$\mathrm{s} \cdot \mathrm{min}^{-1}$, blood pressure $<90 \mathrm{mmHg}$ systolic or diastolic blood pressure $\leqslant 60 \mathrm{mmHg}$, and age $\geqslant 65 \mathrm{yrs}$; PSI: pneumonia severity index . p-value for all parameters $>0.05$, except ${ }^{\#}: p<0.001$.

$\beta$-lactam treatment with or without a macrolide combination was prescribed most frequently (table 3). Therefore, in the following analysis, only patients receiving either $\beta$-lactam with or without a macrolide or MFX monotherapy were included.

Comparing all grades of pneumonia severity, BLM revealed a clear trend to less TF compared with single $\beta$-lactam therapy (BL) $(37(15.5 \%)$ out of 239 patients versus $64(21.5 \%)$ of 297 patients; $\mathrm{p}=0.074)$. However, in $\mathrm{SCAP}$, this tendency was more profound and statistically significant (nine $(12.9 \%)$ out of 70 patients versus $31(26.7 \%)$ out of 116 patients; $\mathrm{p}=0.026)$.

In mild-to-moderate pneumonia (CURB-65 scores 0 and 1), treatment with MFX significantly reduced the rate of TF in comparison with any $\beta$-lactam monotherapy or combination treatment (34 (8.0\%) out of 425 patients versus $86(19.9 \%)$ out of 432 patients; $\mathrm{p}<0.001)$. Interestingly, this difference was not observed in patients with sCAP. In sCAP, the comparable TF rates among treatment groups seemed to be caused mainly by excessive TF rates in patients having received BL. In contrast, application of a BLM or MFX in SCAP was associated with less TF. Directly comparing TF rates of patients being treated with BLM or MFX treatment, there was no significant difference 
among treatment groups (fig. 2). However, after controlling for confounders in multivariate analysis, the adjusted risk of TF was lowest in patients receiving initial MFX treatment (table 5).

\section{Mortality}

A total of $88(7.1 \%)$ out of 1,236 patients died during hospital stay. As expected, mortality rose from $2.3 \%$ in patients with mild pneumonia (CURB-65 score 0 ) to $50 \%$ in patients with four points on the CURB-65 score. The mortality rate was three-fold higher in patients who failed to respond to initial antibiotic treatment $(17.3 \%$ versus $5.2 \%$; $<<0.001)$.

Although the populations of both treatment groups were very comparable with regard to pneumonia severity, demographics and comorbidity, with the exception of a higher proportion of diabetics in MFX-treated patients, mortality differed among groups. Whereas the mortality rate among patients with initial response to therapy was significantly higher in group $S$ compared with patients receiving MFX (6.7\% versus $3.8 \%$; $\mathrm{p}=0.034)$, no significant differences in mortality rates were seen between treatment groups in relation to initial treatment failure $(18.9 \%$ versus $13.8 \%$; $=0.374)$.

\section{Cost results}

Median overall treatment cost for one CAP episode was $€ 1,361.80$ (mean \pm SD $€ 1,602.04 \pm 1,001.77$ ). Treatment costs in successfully treated patients were below the overall median; however, they were almost two-fold higher in failures $(€ 1,284.09$ versus $€ 2,206.11 ; \mathrm{p}<0.001)$. For details see figure 3 . In patients with nonresponding pneumonia (TF after 5 days), mean treatment cost were slightly higher compared with patients with early failure ( 3 days) $(€ 2,756.03 \pm 1,375.92$ versus $€ 2,521.77 \pm 1,861.02$; $\mathrm{p}=0.338)$. This was mainly caused by a significantly extended LOS (16.9 \pm 6.2 days versus $14.0 \pm 7.9$ days; $\mathrm{p}=0.004)$.

CAP severity significantly influenced treatment costs. Mean overall treatment costs constantly rose with an increase in the severity of CAP except in very severe CAP (CURB-65 score $=4$ ).

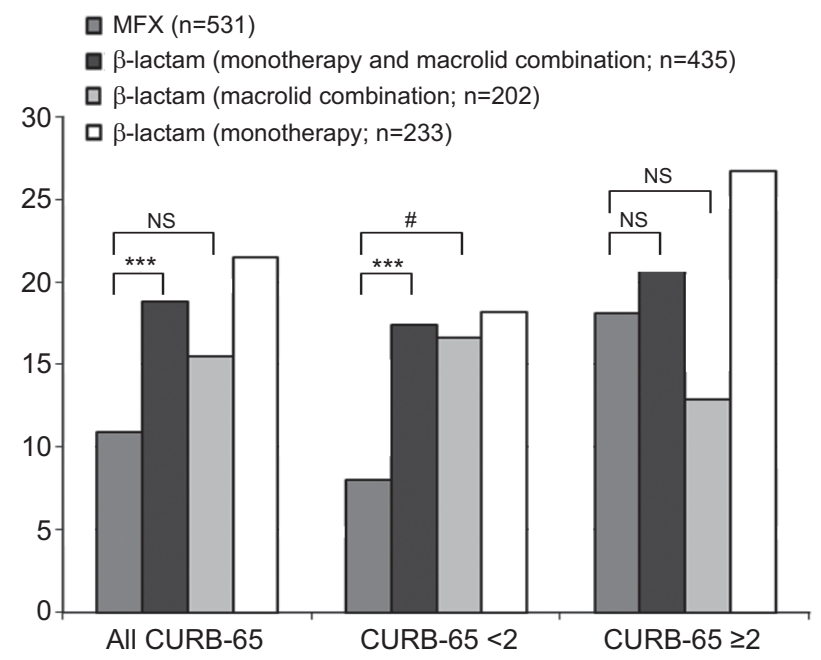

FIGURE 2. Rates of treatment failure according to community-acquired pneumonia severity and antibiotic treatment. CURB-65: confusion of new onset, urea $>7 \mathrm{mmol} \cdot \mathrm{L}^{-1}$, respiratory rate of $\geqslant 30$ breaths $\cdot \mathrm{min}^{-1}$, blood pressure $<90 \mathrm{mmHg}$ systolic or diastolic blood pressure $\leqslant 60 \mathrm{mmHg}$, and age $\geqslant 65 \mathrm{yrs}$; NS: nonsignificant; MFX: moxifloxacin. ${ }^{* * *}: p<0.001$; ${ }^{*}: p=0.002$.
The mean length of hospitalisation was $10.6 \pm 5.2$ days (median 10.0 days, range 1-42 days). TF resulted in a significant prolongation of LOS (15.4 \pm 7.3 days versus $9.8 \pm 4.2$ days; $\mathrm{p}<0.001)$. However, median LOS in group $\mathrm{M}$ was 1 day shorter than in group $\mathrm{S}$ (9 versus 10 days; $\mathrm{p}<0.001)$.

\section{DISCUSSION}

The major findings of this study were as follows: 1) TF contributes to a significant increase in median direct treatment costs from $€ 1,284.09$ to $€ 2,206.11 ; 2$ ) this is mainly because of a significantly prolonged LOS (median 9.0 versus 14.0 days); 3) choice of empirical antibiotic therapy influences the risk of TF depending on CAP severity; and 4) MFX is highly effective in terms of low failure rates, and its efficacy is more comparable with BLM therapy than with BL, especially in SCAP.

The median direct treatment cost for one CAP episode was $€ 1,361.80$ (mean $\pm S D € 1,602.04 \pm 1,001.77$ ), which is in accordance with currently published data. In recent studies, direct treatment costs of in-patient care were estimated to range from US $\$ 1,333$ in Germany [8] and $€ 1,683$ in Spain [7] up to $€ 2,550$ $€ 7,650$ in the UK [15]. Even higher costs per CAP case are found in studies from the USA (US\$5,249-US\$10,227) [16, 17], although the median LOS tended to be longer in Europe. This is interesting as our group previously identified LOS as one of the major contributors to direct treatment costs in German hospitals [8] REYES et al. [7] recently documented that pneumonia-associated complications are a major cause of prolonged LOS and confirmed the relationship between LOS and treatment costs. Many complications of CAP, e.g. persistence of symptoms, progressive respiratory failure and sepsis, are often caused by or are a cause of TF. Accordingly, in our study, patients experiencing TF required a significantly prolonged LOS in comparison to successfully treated patients (mean LOS $15.4 \pm 7.3$ versus $9.8 \pm 4.2$ days), which is similar to the extension of LOS of 4 days caused by TF reported in another recent study [6]. Our data show that TF is associated with significantly higher treatment costs. We therefore postulate that any strategy to prevent TF is of great interest in terms of cost savings.

One strategy for reducing TF is to identify patients who are at risk of TF. Although our study was not designed to identify risk factors for $\mathrm{TF}$, our data suggests congestive heart failure as a risk factor for $\mathrm{TF}$ and is thus in accordance with recent studies $[18,19]$.

As comorbidity cannot be changed, and TF is related mainly to infectious complications, another strategy to avoid TF would be modifications to and/or optimisation of antibacterial therapy. Therefore, we also evaluated the impact of different initial antibiotic regimens on the incidence of TF and, thus, treatment costs.

Increasing CAP severity was associated with higher failure rates and, consequently, increased expenses. However, not only did CURB-65 classes influence TF rates, but also the choice of initial antibiotic treatment was found to modify TF incidence. Compared with BL, TF occurred less frequently in patients who had received initial BLM. Whereas in mild and moderate pneumonia (CURB-65 score $<2$ ), the addition of a macrolide antibiotic had no relevant influence on TF incidence; the occurrence of TF was significantly reduced in sCAP by prescribing BML. This finding supports the results of a recent 


\begin{tabular}{|c|c|c|c|c|c|c|c|}
\hline \multirow[t]{3}{*}{ TABLE 5} & \multicolumn{7}{|c|}{$\begin{array}{l}\text { Crude and adjusted analyses of treatment failure (TF) according to type of antibiotic in } 973 \text { patients with complete } \\
\text { covariate data }\end{array}$} \\
\hline & & \multicolumn{2}{|c|}{ TF } & \multicolumn{2}{|c|}{ Crude analyses } & \multicolumn{2}{|c|}{ Adjusted analyses ${ }^{\#}$} \\
\hline & & Yes & No & OR $(95 \% \mathrm{Cl})$ & p-value & OR $(95 \% \mathrm{Cl})$ & $\mathrm{p}$-value \\
\hline \multicolumn{2}{|c|}{ Type of antibiotic } & & & & $<0.001$ & & $<0.001$ \\
\hline \multicolumn{2}{|c|}{$\beta$-lactam+macrolide } & $23(14)$ & $141(86)$ & $0.71(0.40-1.24)$ & & $0.68(0.38-1.21)$ & \\
\hline \multicolumn{2}{|c|}{ MFX } & $54(10)$ & $469(90)$ & $0.50(0.32-0.78)$ & & $0.43(0.27-0.68)$ & \\
\hline \multicolumn{2}{|l|}{ Other } & $23(29)$ & $55(71)$ & $1.81(1.00-3.30)$ & & $1.79(0.96-3.35)$ & \\
\hline
\end{tabular}

Data are presented as $\mathrm{n}(\%)$, unless otherwise stated. MFX: moxifloxacin; Ref.: reference. ${ }^{\#}$ : adjusted for sex, age, body mass index, smoking, chronic obstructive pulmonary disease, lung cancer, heart disease, diabetes, antibiotic pre-treatment, CURB-65 (confusion of new onset, urea $>7 \mathrm{mmol} \cdot \mathrm{L}^{-1}$, respiratory rate of $\geqslant 30$ breaths $\cdot \mathrm{min}^{-1}$, blood pressure $<90 \mathrm{mmHg}$ systolic or diastolic blood pressure $\leqslant 60 \mathrm{mmHg}$, and age $\geqslant 65$ yrs) and pneumonia severity index

study showing a similar beneficial effect of BML on mortality and incidence of TF, particularly in SCAP [20].

MFX treatment resulted in lower TF rates compared with any $\beta$-lactam monotherapy or combination therapy. This effect was more pronounced in mild pneumonia, where TF was even less frequent in comparison with BLM. Patients with SCAP, having received MFX or BLM, presented comparable TF rates, whereas the rate of TF in patients with SCAP and BL treatment was significantly increased. This observation is also reflected by the lower adjusted OR for TF in BLM- and MFX-treated patients compared with BL (adjusted OR for BLM 0.68 (95\% CI $0.38-1.21 ; \mathrm{p}<0.001)$ and MFX 0.43 (95\% CI 0.27-0.68; $<<0.001$ ), respectively). Interestingly, only for MFX did the confidence interval not include " 1 ", indicating a significant effect. Besides the broader antibacterial coverage by MFX and BLM, a

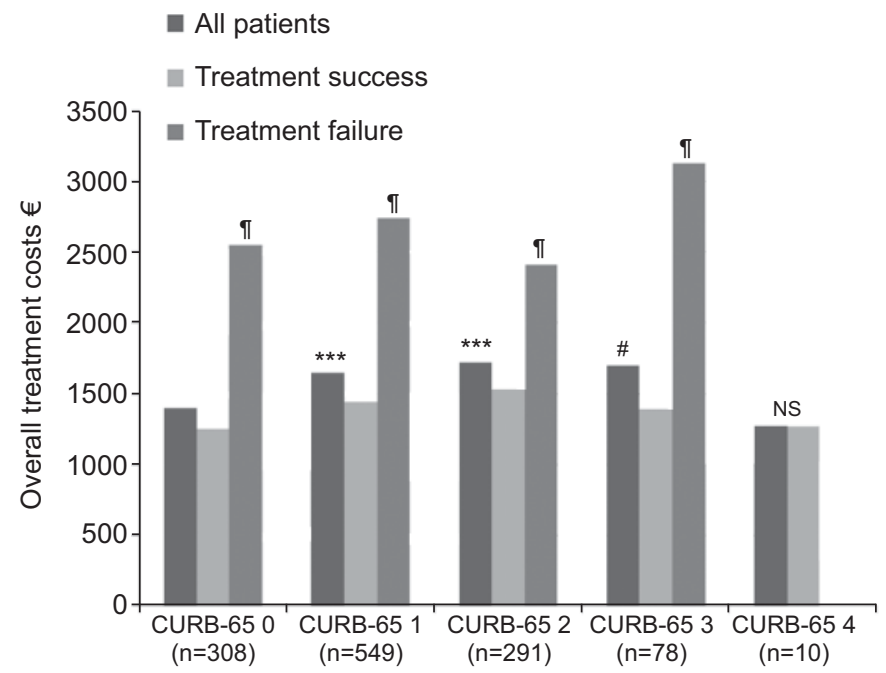

FIGURE 3. Mean overall treatment costs (in Euros) depending on communityacquired pneumonia severity. CURB-65: confusion of new onset, urea $>7 \mathrm{mmol} \cdot \mathrm{L}^{-1}$, respiratory rate of $\geqslant 30$ breaths $\mathrm{min}^{-1}$, blood pressure $<90 \mathrm{mmHg}$ systolic or diastolic blood pressure $\leqslant 60 \mathrm{mmHg}$, and age $\geqslant 65 \mathrm{yrs}$; NS: nonsignificant. \#: $p=0.018$ ( $p$-value for comparison with CURB-65 score 0 ); ${ }^{\top}: p<0.001$ ( $p$-value for comparison with treatment success); ${ }^{* *:} p<0.001$ ( $p$-value for comparison with CURB-65 score 0). previously described immunomodulatory effect of macrolides and some fluoroquinolones may be responsible for the lower TF rate and shorter LOS [21, 22]. Furthermore, differently from $\beta$-lactams, MFX exhibits a concentration-dependent killing of bacteria and is rapidly bactericidal [23]; very high local concentrations at the site of infection can be obtained, because concentrations of MFX in different pulmonary compartments exceed serum concentrations multi-fold [24]. Another explanation for shorter median LOS in MFX-treated patients in our study could be the availability of an oral application of MFX and, thus, easy sequence therapy, as compared with some $\beta$ lactams (e.g. ceftriaxon). Rates of sequence therapies in our study were $79.0 \%$ (group M) versus $52.8 \%$ (group S) $(\mathrm{p}<0.001$ ).

There are some limitations of this study. In the literature, the definition of TF is heterogeneous. Clinical and/or microbiological approaches to defining TF are most commonly used. Usually, patients hospitalised with CAP improve and reach clinical stability within $72 \mathrm{~h}$ after initiation of antimicrobial treatment and a clinical re-evaluation is recommended at that time [25-28]. Some patients show a delayed clinical and/or radiographic improvement, persistence of symptoms, or even clinical deterioration. All these courses of CAP describe different types of clinical failure, and as TF most commonly originates from infectious causes, an adjustment in antibiotic therapy is advised $[5,19]$. An interval of $72 \mathrm{~h}$ is recommended before switching antibiotic therapy, except in cases presenting severe deterioration and/or radiological worsening [28]. The primary objective of our study was the evaluation of the actual direct in-patient costs of CAP treatment, thus, routine clinical or microbiological re-evaluation was not requested in order to avoid influencing treatment costs. Consequently, no data on either short-term clinical outcome $(<72 \mathrm{~h})$ or microbiological success are available. For the post hoc analyses of the economical impact of TF on direct treatment costs, we therefore defined $\mathrm{TF}$ as any change in antibacterial therapy after at $\geqslant 72 \mathrm{~h}$ of treatment, resulting in a broader antimicrobial coverage.

Consequently, no data on the causes for changing initial therapy are available, and some of the modifications in antibiotic treatment may not necessarily reflect TF in terms of persistence or deterioration of symptoms. In some cases, a change of medication might have been caused by adverse drug 
reactions, e.g. a cutaneous reaction. However, as the problemcausing medication could not safely be continued in the affected patient, this may also be considered as TF. However, as the frequency of TF in our study $(15.9 \%)$ is in agreement with recent literature, showing a rate of failure ranging from $6 \%$ to $24 \%$ [3-6], we are convinced that this definition of TF and the frequency found is representative for clinical TF.

Due to its observational nature, randomisation is lacking in our study. Therefore, the number of patients with more severe CAP or clinical suspicion of less common or more resistant microorganisms might correspond with the number of patients treated with fluoroquinolones, as the choice of initial treatment was left to the attending physician's discretion. As there were no differences found in baseline data between the two groups in terms of CAP severity or comorbidities, except for diabetes mellitus, we think that this possible bias can be ruled out.

In our study, the comparator antibiotic regimens were nonstandardised, which suggests the risk of nonadherence to current treatment guidelines. Nonadherence to treatment guidelines is a known risk factor for TF [29] and can increase treatment cost [30]. Given that $89.1 \%$ of the patients in group $S$ received a therapy in accordance with recent guidelines [31-33], including a BLM in $91.6 \%$, nonadherence to treatment guidelines in the nonstandardised cohort cannot explain the different rates in TF and higher costs.

In conclusion, our data demonstrate that $\mathrm{TF}$ results in a significant prolongation of LOS and, consequently, increased treatment costs. Therefore any means of avoiding TF is of great economic interest. As host-associated risk factors for TF can seldom be modified, an optimisation of antimicrobial therapy appears to be a feasible strategy to prevent TF. In our study, initial therapy with BLM was less frequently associated with TF compared with BL, particularly in sCAP. Treatment with MFX seems to be equivalent to BLM. Our results therefore support the treatment recommendations of most national and international guidelines for the use of BLM or respiratory fluoroquinolones in more severe CAP cases [28, 31, 32]. The lowest rate of TF was observed in patients with MFX treatment and milder CAP (CURB-65 score <2). Furthermore, median LOS in MFXtreated patients was 1 day shorter. Therefore, initial treatment with MFX or $\beta$-lactam with or without macrolide is superior to BL and seems to be a possible strategy to avoid TF, especially in sCAP (CURB-65 score $\geqslant 2$ ).

However, taking into account the worldwide emerging threat of antimicrobial resistance, it is crucial to avoid uncritical use of fluoroquinolones. We therefore think that it is important to identify patients at risk for TF who might benefit from antibiotic therapies that are associated with the least TF.

\section{STATEMENT OF INTEREST}

Statements of interest for S.R. Ott, C. Ernen, P.M. Lepper, M.W. Pletz and T. Welte can be found at www.erj.ersjournals.com $/ \mathrm{site} / \mathrm{misc} /$ statements.xhtml

\section{ACKNOWLEDGEMENTS}

We thank all contributors to the study, whose identities cannot be disclosed herein due to the confidentiality agreement reached prior to the study. We thank J. Hamacher (Pulmonology, Linden Hospital, Berne, Switzerland) for critically reading the manuscript.

\section{REFERENCES}

1 Ewig S, Birkner N, Strauss R, et al. New perspectives on community-acquired pneumonia in 388406 patients. Results from a nationwide mandatory performance measurement programme in healthcare quality. Thorax 2009; 64: 1062-1069.

2 Gulsvic A. Major respiratory diseases. In: Loddenkemper GG, Gibson GJ, Sibille R, eds. European Lung White Book. Sheffield, European Respiratory Society, 2003; pp. 55-64.

3 Menéndez R, Torres A, Zalacaín R, et al. Risk factors of treatment failure in community acquired pneumonia: implications for disease outcome. Thorax 2004; 59: 960-965.

4 Genne D, Kaiser L, Kinge TN, et al. Community-acquired pneumonia: causes of treatment failure in patients enrolled in clinical trials. Clin Microbiol Infect 2003; 9: 949-954.

5 Arancibia F, Ewig S, Martinez JA, et al. Antimicrobial treatment failures in patients with community-acquired pneumonia: causes and prognostic implications. Am J Respir Crit Care Med 2000; 162: 154-160.

6 Genné D, Sommer R, Kaiser L, et al. Analysis of factors that contribute to treatment failure in patients with community-acquired pneumonia. Eur J Clin Microbiol Infect Dis 2006; 25: 159-166.

7 Reyes S, Martinez R, Vallés JM, et al. Determinants of hospital costs in community-acquired pneumonia. Eur Respir J 2008; 31: 1061-1067.

8 Bauer TT, Welte T, Ernen C, et al. Cost analyses of communityacquired pneumonia from the hospital perspective. Chest 2005; 128: 2238-2246.

9 Marrie TJ, Lau CY, Wheeler SL, et al. A controlled trial of a critical pathway for treatment of community-acquired pneumonia. CAPITAL Study Investigators. Community-Acquired Pneumonia Intervention Trial Assessing Levofloxacin. JAMA 2000; 283: 749-755.

10 Drummond MF, Becker DL, Hux M, et al. An economic evaluation of sequential i.v./po moxifloxacin therapy compared to i.v./po co-amoxiclav with or without clarithromycin in the treatment of community-acquired pneumonia. Chest 2003; 124: 526-535.

11 Menéndez R, Torres A, Rodríguez de Castro F, et al. Reaching stability in community-acquired pneumonia: the effects of the severity of disease, treatment, and the characteristics of patients. Clin Infect Dis 2004; 39: 1783-1790.

12 Bauer TT, Ewig S, Marre R, et al. CRB-65 predicts death from community-acquired pneumonia. J Intern Med 2006; 260: 93-101.

13 Fine MJ, Auble TE, Yealy DM, et al. A prediction rule to identify low-risk patients with community-acquired pneumonia. $N$ Engl J Med 1997; 336: 243-250.

14 Critical Assesment of Economic Evaluation. In: Drummond MF, Sculpher MJ, Torrance GW, et al, eds. Methods for the Economic Evaluation of Health Care Programs. Oxford, Oxford University Press, 1987; pp. 18-32.

15 Guest JF, Morris A. Community-acquired pneumonia: the annual cost to the National Health Service in the UK. Eur Respir J 1997; 10: 1530-1534.

16 Fine MJ, Pratt HM, Obrosky DS, et al. Relation between length of hospital stay and costs of care for patients with communityacquired pneumonia. Am J Med 2000; 109: 378-385.

17 Colice GL, Morley MA, Asche C, et al. Treatment costs of community-acquired pneumonia in an employed population. Chest 2004; 125: 2140-2145.

18 Musher DM, Rueda AM, Kaka AS, et al. The association between pneumococcal pneumonia and acute cardiac events. Clin Infect Dis 2007; 45: 158-165.

19 Aliberti S, Amir A, Peyrani P, et al. Incidence, etiology, timing and risk factors for clinical failure in hospitalized patients with community-acquired pneumonia. Chest 2008; 134: 955-962.

20 Tessmer A, Welte T, Martus $\mathrm{P}$, et al. Impact of intravenous $\beta$ lactam/macrolide versus $\beta$-lactam monotherapy on mortality in hospitalized patients with community-acquired pneumonia. J Antimicrob Chemother 2009; 63: 1025-1033.

21 Dalhoff A, Shalit I. Immunomodulatory effects of quinolones. Lancet Infect Dis 2003; 3: 359-371. 
22 Parnham MJ. Immunomodulatory effects of antimicrobials in the therapy of respiratory tract infections. Curr Opin Infect Dis 2005; 18: 125-131.

23 Dalhoff A, Petersen U, Endermann R. In vitro activity of BAY 128039, a new 8-methoxyquinolone. Chemotherapy 1996; 42: 410-425.

24 Soman A, Honeybourne D, Andrews J, et al. Concentrations of moxifloxacin in serum and pulmonary compartments following a single $400 \mathrm{mg}$ oral dose in patients undergoing fibre-optic bronchoscopy. J Antimicrob Chemother 1999; 44: 835-838.

25 Halm EA, Fine MJ, Marrie TJ, et al. Time to clinical stability in patients hospitalized with community-acquired pneumonia: implications for practice guidelines. JAMA 1998; 279: 1452-1457.

26 Montravers P, Fagon JY, Chastre J, et al. Follow-up protected specimen brushes to assess treatment in nosocomial pneumonia. Am Rev Respir Dis 1993; 147: 38-44.

27 Ortqvist A, Kalin M, Lejdeborn L, et al. Diagnostic fiberoptic bronchoscopy and protected brush culture in patients with community-acquired pneumonia. Chest 1990; 97: 576-582.

28 Mandell LA, Wunderink RG, Anzueto A, et al. Infectious Diseases Society of America/American Thoracic Society consensus guidelines on the management of community-acquired pneumonia in adults. Clin Infect Dis 2007; 44: Suppl. 2, S27-S72.
29 Menéndez R, Torres A, Zalacaín R, et al. Guidelines for the treatment of community-acquired pneumonia: predictors of adherence and outcome. Am J Respir Crit Care Med 2005; 172: 757-762.

30 Menendez R, Reyes S, Martinez R, et al. Economic evaluation of adherence to treatment guidelines in nonintensive care pneumonia. Eur Respir J 2007; 29: 751-756.

31 Woodhead M, Blasi F, Ewig S, et al. Guidelines for the management of adult lower respiratory tract infections. Eur Respir J 2005; 26: $1138-1180$.

32 Höffken G, Lorenz J, Kern W, et al. Epidemiologie, Diagnostik, antimikrobielle Therapie und Management von erwachsenen Patienten mit ambulant erworbenen tiefen Atemwegsinfektionen sowie ambulant erworbener Pneumonie - update 2009 [Epidemiology, diagnosis, antimicrobial therapy and management of community-acquired pneumonia and lower respiratory tract infections in adults. Guidelines of the Paul-Ehrlich-Society for Chemotherapy, the German Respiratory Society, the German Society for Infectiology and the Competence Network CAPNETZ Germany]. Pneumologie 2009; 63: e1-68.

33 Lim WS, Baudouin SV, George RC, et al. BTS guidelines for the management of community acquired pneumonia in adults: update 2009. Thorax 2009; 64: Suppl. 3, iii1-iii55. 